\title{
ARTICLE Aspirin inhibits the proliferation of hepatoma cells through controlling GLUT1-mediated glucose metabolism
}

\author{
Yun-xia Liu ${ }^{1}$, Jin-yan Feng ${ }^{1}$, Ming-ming Sun ${ }^{1}$, Bo-wen Liu ${ }^{2}$, Guang Yang ${ }^{1}$, Ya-nan Bu ${ }^{1}$, Man Zhao ${ }^{1}$, Tian-jiao Wang ${ }^{2}$, Wei-ying Zhang ${ }^{1}$, \\ Hong-feng Yuan ${ }^{1}$ and Xiao-dong Zhang ${ }^{1}$
}

\begin{abstract}
Aspirin can efficiently inhibit liver cancer growth, but the mechanism is poorly understood. In this study, we report that aspirin modulates glucose uptake through downregulating glucose transporter 1 (GLUT1), leading to the inhibition of hepatoma cell proliferation. Our data showed that aspirin significantly decreased the levels of reactive oxygen species (ROS) and glucose consumption in hepatoma cells. Interestingly, we identified that GLUT1 and HIF1a could be decreased by aspirin. Mechanically, we demonstrated that the $-1008 /-780$ region was the regulatory element of transcriptional factor NF-KB in GLUT1 promoter by luciferase report gene assays. PDTC, an inhibitor of NF-KB, could suppress the expression of GLUT1 in HepG2 and H7402 cells, followed by affecting the levels of ROS and glucose consumption. $\mathrm{CoCl}_{2}$-activated HIF1a expression could slightly rescue the GLUT1 expression inhibited by aspirin or PDTC, suggesting that aspirin depressed GLUT1 through targeting NF-KB or NF-KB/HIF1a signaling. Moreover, we found that GLUT1 was highly expressed in clinical HCC tissues relating to their paired adjacent normal tissues. Importantly, we observed that high level of GLUT1 was significantly correlated with the poor relapse-free survival of HCC patients by analysis of public data. Functionally, overexpression of GLUT1 blocked the PDTC-induced or aspirin-induced inhibition of glucose metabolism in HepG2 cells. Conversely, aspirin failed to work when GLUT1 was stably knocked down in the cells. Administration of aspirin could depress the growth of hepatoma cells through controlling GLUT1 in vitro and in vivo. Thus, our finding provides new insights into the mechanism by which aspirin depresses liver cancer.
\end{abstract}

Keywords: aspirin; glucose uptake; GLUT1; NF-KB; liver cancer

Acta Pharmacologica Sinica (2019) 40:122-132; https://doi.org/10.1038/s41401-018-0014-x

\section{INTRODUCTION}

Hepatocellular carcinoma (HCC) is the second most common cause of cancer-related death worldwide [1-4]. In contrast to many other cancers, its incidence increases annually by $1.75 \%$ in the western world [5]. In addition to hepatitis B, hepatitis C, alcohol and metabolic syndromes, such as diabetes and obesity, have also been proposed as major risk factors for HCC [1, 6]. Altered energy metabolism is regarded as one of the hallmarks of cancer. Cancer cells preferentially use aerobic glycolysis to meet their increased energetic and biosynthetic demands, a phenomenon known as the Warburg effect [7]. As such, increased aerobic glycolysis is a widely observed feature and often correlates with tumor aggressiveness and poor patient prognosis in HCC [8]. Endogenous reactive oxygen species (ROS), the byproduct of oxidative phosphorylation, presents the process of aerobic metabolism [9]. To meet the increased metabolic activity and rapid proliferation, cancer cells utilize glucose as the main energy substrate by facilitative transport systems. Glucose transporter 1 (GLUT1), also known as solute carrier family 2 (SLC2A1), promotes the transport of glucose across the plasma membranes of mammalian cells [10]. GLUT1 expression is primarily undetectable in normal epithelial tissues and benign epithelial tumors while it is overexpressed in a significant proportion of human carcinoma [11, 12]. The elevated GLUT1 expression in liver cancer indicates increasingly metabolic states and associates with aggressive metastatic behavior [13, 14]. However, it is unclear whether aspirin affects abnormal glucose metabolism through modulating the expression of GLUT1 in liver cancer.

Aspirin is widely prescribed as a painkiller, antipyretic, or antiplatelet agent for more than 100 years, which has been shown to have anti-inflammatory effects through different mechanisms, including inhibition of cyclooxygenase- 2 and nuclear factor $\mathrm{KB}$ (NF-KB) $[15,16]$. Long-term follow-up study in several trials demonstrates that the nonsteroid anti-inflammatory agent aspirin prevents the development of HCC, colorectal adenomas, breast and pancreatic cancers [14, 17-20]. Our group has reported that aspirin is capable of suppressing the abnormal lipid metabolism in HCC cells [21]. In addition, aspirin treatment also resulted in a reduction in basal rates of glucose production and an improvement in insulin-stimulated peripheral glucose uptake under matched plasma insulin concentrations during the clamp [22]. However, whether aspirin can regulate the glucose metabolism in suppression of liver cancer proliferation is poorly understood.

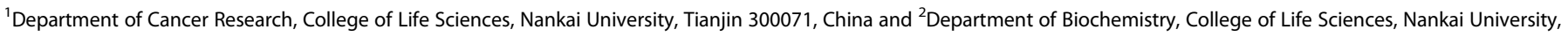
Tianjin 300071, China

Correspondence: Xiao-dong Zhang (zhangxd@nankai.edu.cn)

These authors contributed equally: Yun-xia Liu and Jin-yan Feng.

Received: 23 October 2017 Accepted: 31 January 2018

Published online: 20 June 2018 
In this study, we are interested in the effects of aspirin on glucose metabolism in liver cancer. Our data show that aspirin modulates glucose uptake through decreasing the level of GLUT1, leading to the inhibition of hepatoma cell proliferation. Our finding provides new insights into the mechanism by which aspirin regulates the glucose metabolism in HCC.

\section{MATERIALS AND METHODS}

Patient samples

Thirty HCC tissue samples and their corresponding adjacent normal tissues were obtained from Tianjin First Center Hospital and Tianjin Tumor Hospital (Tianjin, China) after surgical resection. Written consent approving the use of tissue samples for research purposes after surgery was obtained from each patient. The study protocol was approved by the Institute Research Ethics Committee at Nankai University (Tianjin, China). The medical records of the patients are listed in Supplementary Table S1.

Cell culture

The human hepatoma cell line HepG2 was maintained in DMEM medium (Gibco, CA, USA). The human hepatoma cell line H7402 was cultured in RPMI-1640 medium (Gibco, CA, USA). The human embryonic kidney (HEK) 293T cell line was maintained in DMEM medium (Gibco, CA, USA). All cell lines were supplemented with heat-inactivated $10 \%$ FBS (FBS, Gibco, CA, USA), $100 \mathrm{U} / \mathrm{mL}$ penicillin, and $100 \mathrm{mg} / \mathrm{mL}$ streptomycin and grown at $5 \% \mathrm{CO}_{2}$ and $37^{\circ} \mathrm{C}$.

\section{Aspirin and PDTC treatment}

Cells were treated with 2 and $4 \mathrm{mM}$ aspirin (Sigma-Aldrich, St. Louis, MO, USA) for specific experiments [18, 23]. The concentrations of aspirin administration were remarkably lower than its $I C_{50}$ [24]. Because aspirin is sparingly soluble in distilled water, the $1 \mathrm{M}$ stock solution was prepared in DMSO. For all in vitro assays with aspirin, DMSO was used as control. Cells were treated with 25 and $50 \mu \mathrm{M}$ pyrrolidine dithiocarbamate (PDTC, Sigma, St. Louis, USA).

ROS assays

HepG2 and H7402 cells were treated with 2 and $4 \mathrm{mM}$ aspirin for $48 \mathrm{~h}$, and then the cells were incubated with FBS-free culture medium containing $10 \mu \mathrm{M}$ DCFH-DA for $20 \mathrm{~min}$ at $37^{\circ} \mathrm{C}$. DCFH-DA was metabolized by the non-specific esterase to the nonfluorescence product, DCFH, which was oxidized to the fluorescent product, DCF, by ROS. The cells were washed three times with PBS to remove the unabsorbed DCFH-DA and then trypsinized, resuspended in PBS, and measured for their ROS using flow cytometry. All of the experiments were performed according to the manufacturer's recommended protocols.

\section{Glucose consumption detection}

HepG 2 or H7402 cells were treated with 2 and 4 mM aspirin for 48 $h$, the supernatant was collected and used for measurement of glucose consumption by glucose-lactate biosense tester SBA-40E (Institute of Biology, Shandong Academy of Sciences, Ji'nan, China). All of the experiments were performed according to the manufacturer's recommended protocols.

Immunohistochemistry

The microarrays including HCC tissues and normal liver tissues were obtained from the Xi'an Aomei Biotechnology Co., Ltd. (03C03, Xi'an, China). Clinicopathological information about the patients was obtained from patient records, and was summarized in Supplementary Table S2. These microarrays were composed of 143 HCC tissues and 8 normal liver tissues, which included duplicate core biopsies ( $1 \mathrm{mM}$ in diameter) from fixed, paraffinembedded tumors. Immunohistochemical staining of samples were performed as previously reported [25] and the primary antibody of rabbit anti-GLUT1 was used. The percentage of immune reactivity in tumor cells or hepatocytes was graded as: 0 $(<10 \%) ; 1$, low $(10 \%-30 \%) ; 2$, intermediate $(30 \%-50 \%) ; 3$, high $(>50 \%)$. Categorization of immunostaining intensity was performed by three independent observers.

EdU

Five-ethynyl-2'-deoxyuridine can be used to label cells undergoing DNA replication. The EdU assay was performed using the CellLight $^{\mathrm{TM}}$ EdU imaging detection kit (RiboBio, China) according to the manufacturer's instructions.

\section{Plasmid construction}

GLUT1 was cloned into vector pcDNA3.1 (Hind III, Xho I) (forward primer, 5'-CCAAGCTTATGGAGCCCAGCAGCAAGAAGCTGA-3'; reverse primer, 5'-CCCTCGAGTCACACTTGGGAATCAGCCCCCAGG-3'). Various lengths of the GLUT1 $5^{\prime}$ flanking region, including $-1306 /+197$ (pGL3-P1), -1008/+197 (pGL3-P2), -780/+197 (pGL3-P3), -459/ +197 (pGL3-P4), -126/+197 (pGL3-P5) and -1306/+197 (pGL3-P1 mut) were cloned, respectively. The following primers were used to construct these vectors: pGL3-P1 forward primer, 5'-CTAGCTAG CCTGGTCGGCTCAGCCTCCCGGT-3'; pGL3-P2 forward primer, 5'-CT AGCTAGCTAAACCAACAATACCACCAACCAGT-3'; pGL3-P3 forward primer, 5'-CTAGCTAGCAAAATGGTGAAACCCCGTCTCTACT-3'; pGL3P4 forward primer, 5'-CTAGCTAGCTCAGTCAGTTAGCCTGCCTITCA TA-3'; pGL3-P5 forward primer, 5'-CTAGCTAGCCTACGAGGTGGTACTGTTACTATCC-3'; reverse primer, 5'-CCGCTCGAGCTGTCCTGGGC GGCGCTCTG-3'; pGL3-P1 mut forward primer, 5'-AGCTTATCTGCATAATCGACCTCTC-3'; pGL3-P1 mut reverse primer, 5'-ATCAGGAGAGGTCGATTATGCAGATA-3'.

Construction and production of plasmids and recombinant lentiviral vectors

The recombinant lentiviral vector pLKO.1 was used to knock-down GLUT1 expression in HepG2 cells. The lentiviral vector was transfected into 293T cells with the psPAX, pMD2.G packaging mix using the Lipofectamine 2000 reagent (Invitrogen Co, Carlsbad, CA, USA). The viruses were harvested after 24 and $36 \mathrm{~h}$ and mixed with HepG2 in the presence of $8 \mu \mathrm{g} / \mathrm{mL}$ polybrene. Transduced cells were selected with $3 \mathrm{ng} / \mathrm{mL}$ of puromycin 3 days after virus transduction. Knock-down was confirmed using realtime quantitative polymerase chain reaction (PCR) and Western blot. The selected sequences were as follows: GLUT1 shRNA sequences 1: (F) 5'-CCGG GGAATTCAATGCTGATGATGACTCGAGTCATCATCAGCATTGAATTCCTITTG-3', (R) 5'-AATTCAAAAAGGAATTCAATGCTGATGATGACTCGAGTCATCATCAGCATTGAATTCC- ${ }^{\prime \prime}$; The shRNA target sequence is underlined. The cells were independently divided into two groups: control (untransduced group), shGLUT1.

Cell viability assays

The 3-(4,5-dimethylthiazol-2-yl)-2,5-diphenyltetrazolium bromide (MTT) assays were performed as previously described [26]. In brief, cells were harvested from exponential phase cultures, counted, and plated in 96 -well plates at $3 \times 10^{3}$ cells per well. Twenty-four hours later, the cells were incubated with the MTT substrate (20 $\mathrm{mg} / \mathrm{mL}$ ) for $4 \mathrm{~h}$. After incubation, the culture medium was removed, and dimethyl sulfoxide was added. Optical density was measured at 490 and $620 \mathrm{~nm}$. Accordingly, cell proliferation was measured by MTT assays each day for 3 days $[27,28]$.

Luciferase reporter gene assays

Luciferase reporter gene assay was performed using the DualLuciferase Reporter Assay System (Promega) according to the manufacturer's instructions. 293T cells and HepG2 cells respectively were transferred into 24 -well plates at $3 \times 10^{4}$ cells per well. After $24 \mathrm{~h}$, the cells were transiently co-transfected with 

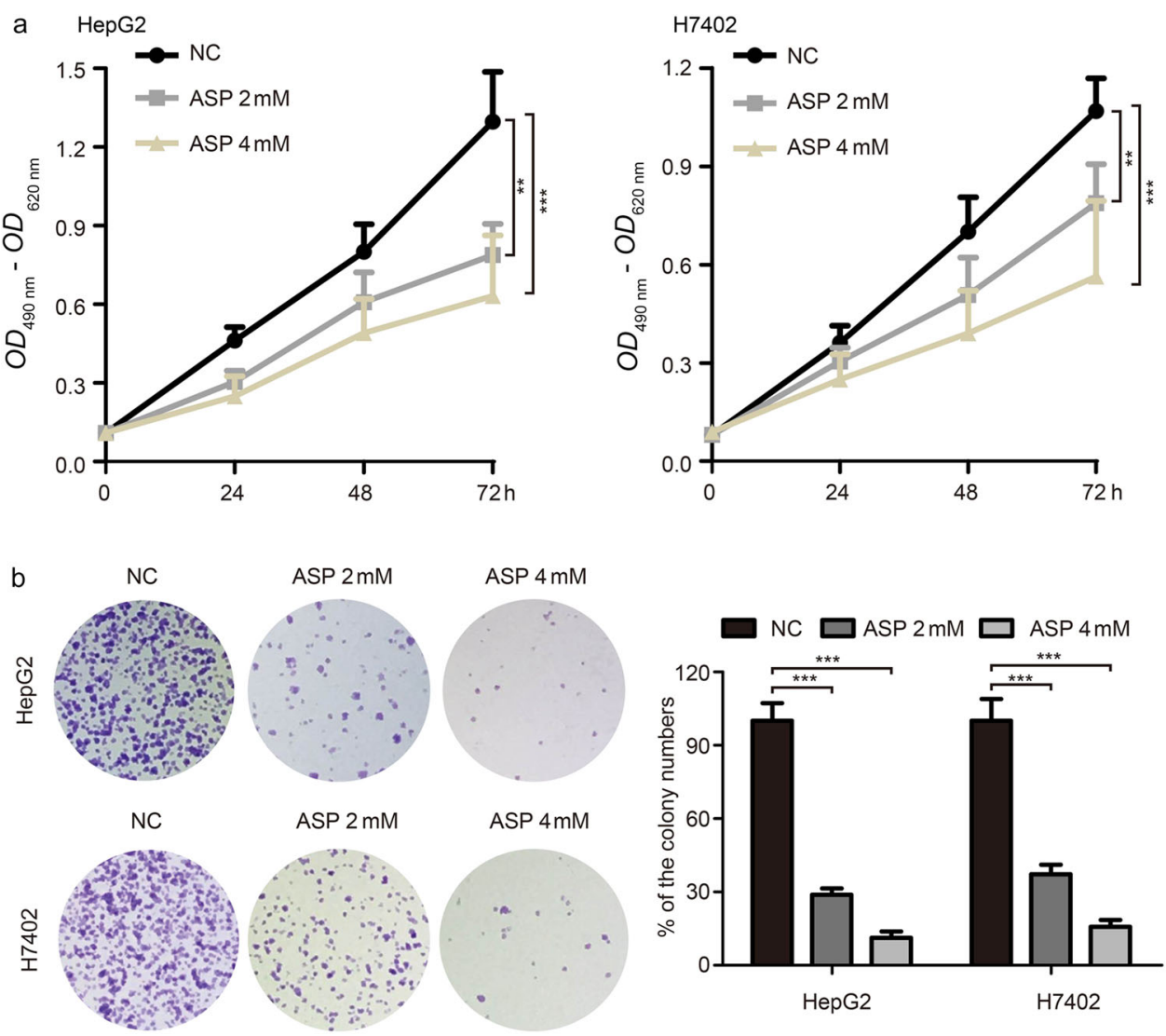

ASP $2 \mathrm{mM}$

ASP $4 \mathrm{mM}$
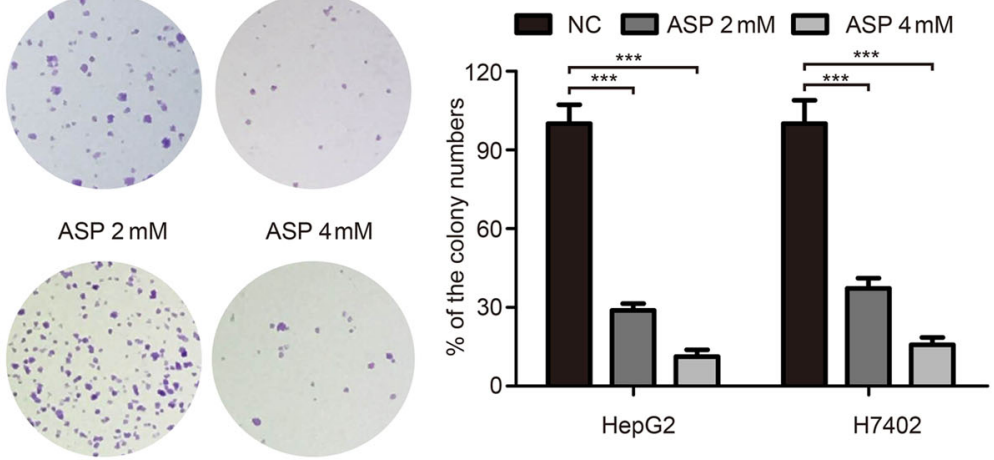

C
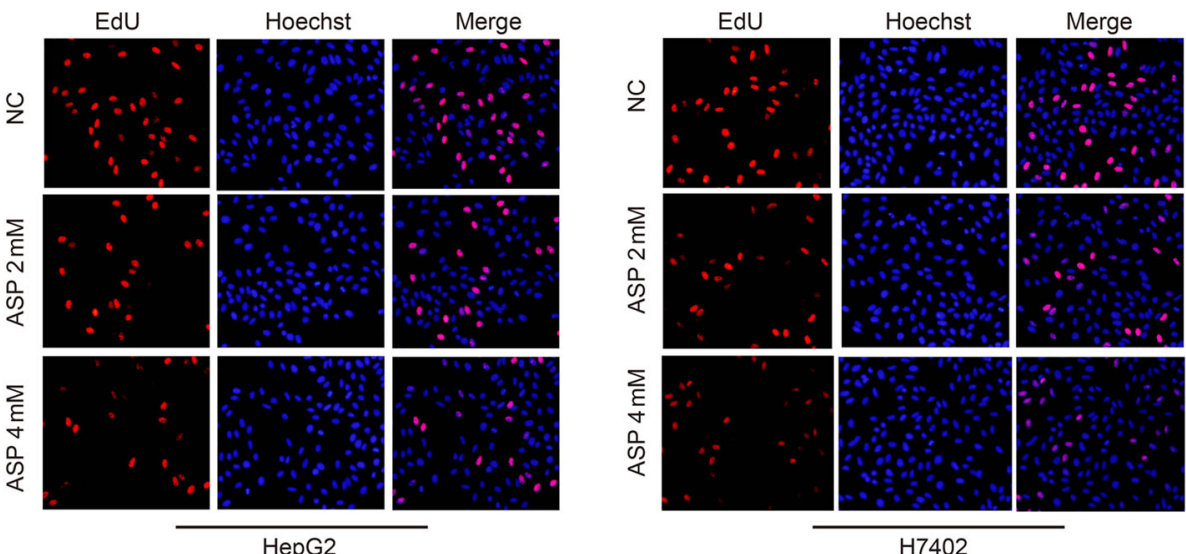

$\mathrm{H} 7402$

Fig. 1 Aspirin suppresses the proliferation of liver cancer cells in vitro. a Cell viability assays in HepG2 and H7402 cells treated with different concentrations of aspirin for indicated time courses. b Colony photograph and colony forming efficiency in HepG2 cells and H7402 cells treated with different concentrations of aspirin for 20 days. c EdU assays in HepG2 cells and H7402 cells treated with different concentrations of aspirin for $48 \mathrm{~h}$. Statistical significant differences are indicated: ${ }^{*} P<0.05,{ }^{* * *} P<0.001$, Student's $t$-test for (a), One-way ANOVA for (b, right). All experiments were performed at least three times

$0.05 \mu \mathrm{g} /$ well of pRL-TK plasmid (Promega, Madison, WI, USA) containing the Renilla luciferase gene used for internal normalization, and various constructs containing different lengths of the GLUT1 5'-flanking region or pGL3-Basic. The luciferase activities were measured as previously described [3]. All experiments were performed at least three times.

\section{Xenograft}

Five to six week-old male BALB/c athymic nude mice (Experiment Animal Center of Peking, China) were housed and treated according to guidelines established by the National Institutes of Health Guide for the Care and Use of Laboratory Animals. On day
0 , HepG2 cells were harvested and suspended at $2 \times 10^{7}$ cells $/ \mathrm{mL}$ in $0.2 \mathrm{~mL}$ of PBS in separate sets of mice, and then injected into the right subaxillary region of each mouse. When the tumor size reached about $100 \mathrm{~mm}^{3}$, mice were randomized into two treatment groups by simple randomization method, and 5 mice in each group were treated daily by intragastric gavage (ig) with either (i) normal saline (Vehicle) (ii) aspirin (suspended in physiological saline, $75 \mathrm{mg}$ per $\mathrm{kg}$ ). After 30 days, mice were euthanized and tumors were sectioned and fast-frozen, or formalin-fixed and paraffin-embedded slides were made. The tumor volume and body weight were measured twice a week. Blind measurements were carried out to avoid unconscious biases. 
a

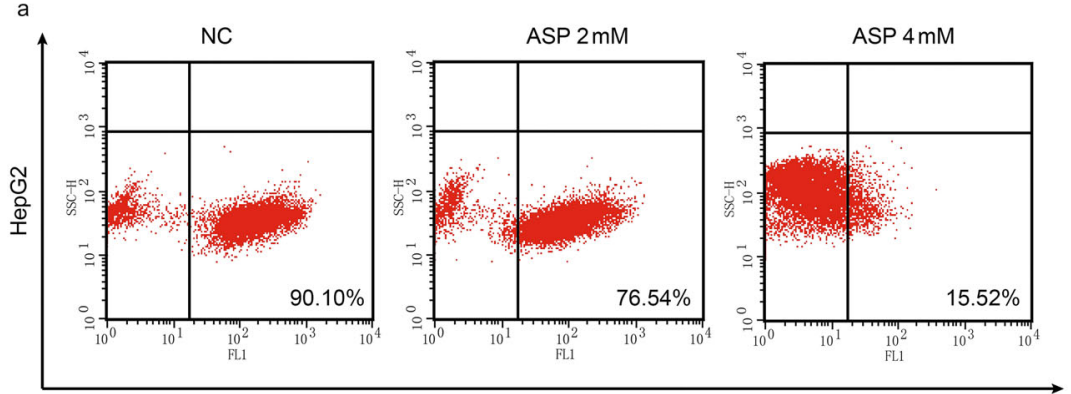

b
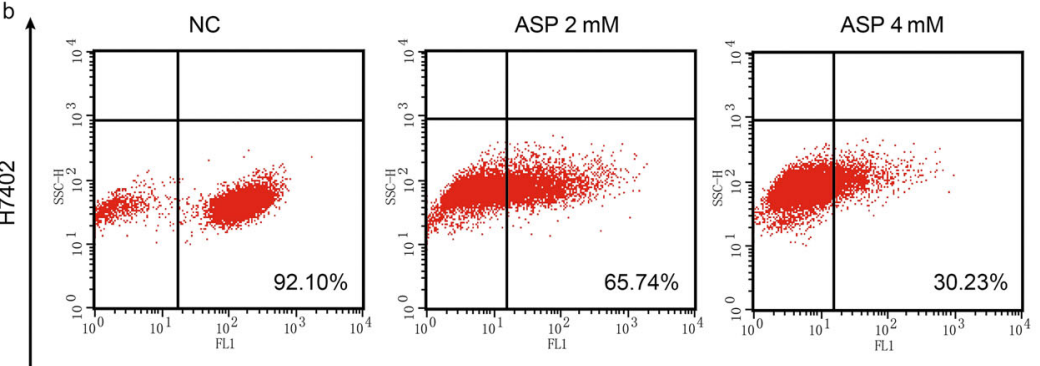

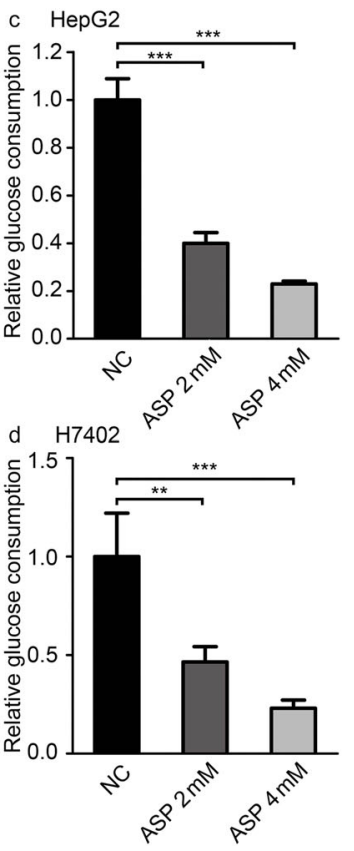

Fig. 2 Aspirin decreases the levels of ROS and glucose consumption in liver cancer cells. $\mathbf{a}$, b The intracellular ROS levels were measured by flow cytometry in HepG2 cells (a) and H7402 cells (b). c, d Glucose consumption assays in HepG2 cells (c) and H7402 cells (d). The supernatant treated with different concentrations of aspirin were used for measurement of glucose by glucose-lactate biosense tester SBA-40E. Statistical significant differences are indicated: ${ }^{* *} P<0.01,{ }^{* * *} P<0.001$, One-way ANOVA. All experiments were performed at least three times

Tumor volume $(V)$ was monitored by measuring the length $(L)$ and width $(W)$ with calipers and calculated with the formula $\left(L \times W^{2}\right) \times$ 0.5 .

\section{Statistical analysis}

All data were performed in three independent experiments. Student's $t$-test was used for comparisons between two groups. One-way ANOVA was employed to analyze variance for comparisons between three or more groups. Gehan-Breslow-Wilcoxon test was used for relapse-free survival analysis of 49 HCC patients with low versus high GLUT1 expression. Statistically significant $P$ values were indicated in figures as follows: ${ }^{*} P<0.05,{ }^{* *} P<0.01$ and ${ }^{* *} P<0.001$ using the SPSS software program (SPSS, Chicago, USA).

\section{RESULTS}

Aspirin inhibits the proliferation of liver cancer cells in vitro It's well known that aspirin depresses cell proliferation in many cancers [29-34]. To test the effects of aspirin on liver cancer cells, we performed cell viability, colony-formation and EdU assays in HepG2 and H7402 cells with different concentrations of aspirin. The assays clearly showed that aspirin inhibited cell viability in HepG2 and H7402 cells treated with 2 and $4 \mathrm{mM}$ aspirin for indicated time courses (Fig. 1a). Colony formation assays and EdU assays were consistent with aforesaid results (Fig. 1b, c). We conclude that aspirin is able to suppress the proliferation of liver cancer cells.

Aspirin decreases the levels of ROS and glucose consumption in liver cancer cells

Majority of cancer cells preferentially use aerobic glycolysis instead of oxidative phosphorylation to meet their increased energetic and biosynthetic demands, which is a hallmark of cancer cells [7]. In this study, we concerned whether aspirin could modulate the glucose metabolism in HCC. Following cellular uptake, glucose can be further metabolized to generate ATP by glycolysis/oxidative phosphorylation, and ROS has often been thought of as byproducts of respiratory metabolism [9]. Therefore, we examined the effects of aspirin on ROS production and glucose uptake. Accordingly, ROS assays and glucose consumption assays showed that aspirin significantly decreased intracellular ROS levels and reduced glucose consumption in HepG2 and H7402 cells in a dose-dependent manner (Fig. 2a-d), suggesting that aspirin can affect aerobic glycolysis. In conclusion, our data demonstrate that aspirin decreases the levels of ROS and glucose consumption in liver cancer cells.

Aspirin downregulates the GLUT1 expression through suppressing its transcriptional activities in hepatoma cells

Next, we tried to identify the mechanism by which aspirin regulated glucose metabolism in the suppression of cell proliferation in liver cancer. Then, we examined the effect of aspirin ( $2 \mathrm{mM})$ on those glucose metabolism related factors, including GLUT1, glucose 6-phosphate dehydrogenase (G6PD), hypoxia-inducible factor 1a (HIF1a), cytochrome $c$ oxidase 2 (SCO2) and pyruvate dehydrogenase alpha 1 (PDHA1) [35-37], in HepG2 cells. RT-qPCR revealed that GLUT1 and HIF1a (hypoxia gene) were downregulated in HepG2 cells (Fig. 3a). Then, we further investigated the roles of GLUT1 (and HIF1a) in depression of liver cancer mediated by aspirin. Next, we further evaluated the effect of aspirin on the expression of the GLUT1. As expected, RT-PCR and Western blot assays showed that the administration of aspirin could remarkably decrease the expression of GLUT1 at mRNA and protein levels in HepG2 and H7402 cells (Fig. 3b). Meanwhile, RTqPCR validated the aforesaid data (Fig. $3 c$, d), validating that aspirin can downregulate GLUT1 expression in hepatoma cells. Then, we managed to clarify the mechanism by which aspirin downregulated GLUT1. Interestingly, luciferases reporter gene assays showed that aspirin could decrease the activities of GLUT1 promoter in 293T and HepG2 cells in a dose-dependent manner (Fig. 3e, f). Therefore, we conclude that aspirin can decrease the 


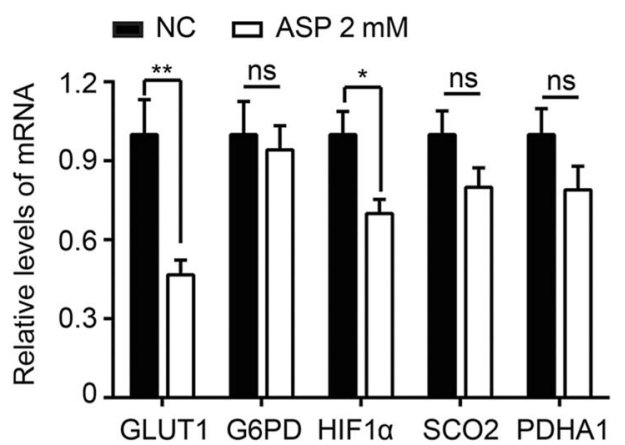

b

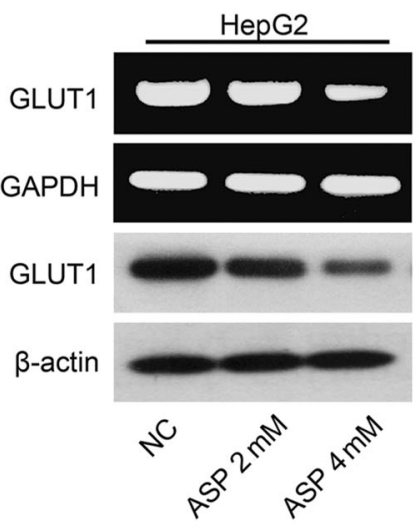

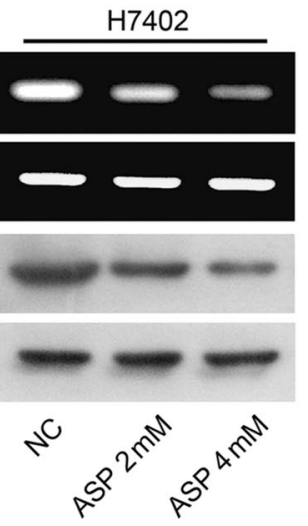

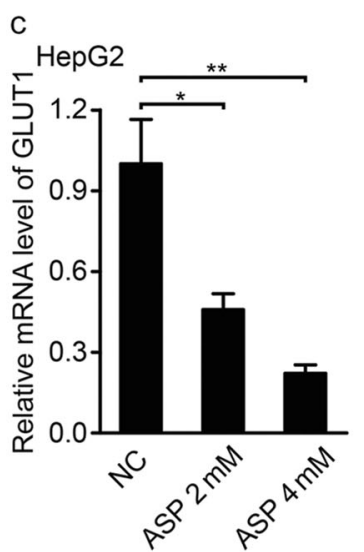

e

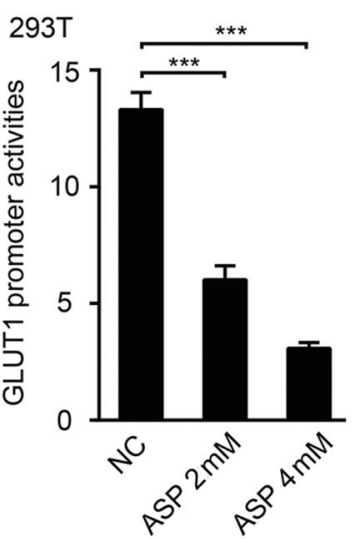

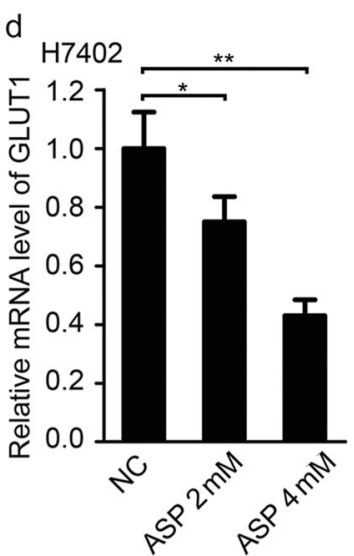

f

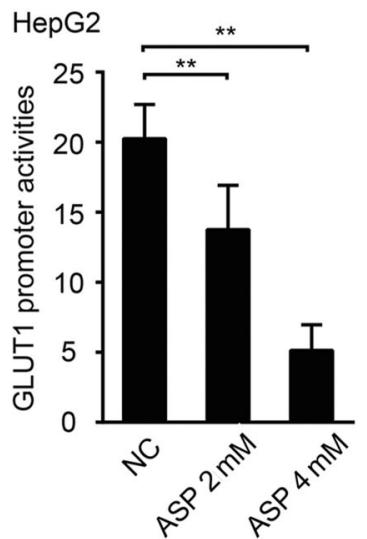

Fig. 3 Aspirin downregulates the GLUT1 expression through suppressing its transcriptional activities in hepatoma cells. a The cells were treated with indicated concentrations $(2 \mathrm{mM})$ of aspirin for $48 \mathrm{~h}$. The mRNA of GLUT1, G6PD, HIF1 $\alpha$, SCO2, and PDHA1 were examined by RTqPCR. b The expression levels of GLUT1 were separately detected by RT-PCR and Western blot assay, in HepG2 (left) and H7402 cells (right). The cells were treated with indicated concentrations of aspirin for $48 \mathrm{~h}$. c The expression levels of GLUT1 in HepG2 cells were separately detected by RT-qPCR assay. d The expression levels of GLUT1 in H7402 cells were separately detected by RT-qPCR assay. e Luciferase reporter gene assay was detected in 293T cells transiently transfected with pGL3-P1 (0.2 $\mathrm{\mu g} / \mathrm{well})$ and treated with indicated concentrations of aspirin $(0,2,4 \mathrm{mM})$ for $48 \mathrm{~h}$. $\mathbf{f}$ Luciferase reporter gene assay were measured in HepG2 cells transiently transfected with pGL3-P1 (0.2 $\mu \mathrm{g} / \mathrm{well})$ and treated with indicated concentrations of aspirin for $48 \mathrm{~h}$. Statistical significant differences are indicated: ${ }^{*} P<0.05,{ }^{* *} P<0.01, * * * P<0.001$, Student's $t$-test for (a), one-way ANOVA for $(\mathbf{c}-\mathbf{f})$. All experiments were performed at least three times

expression of GLUT1 through inhibiting the transcription of GLUT1.

Aspirin regulates the expression of GLUT1 via NF-KB or NF-KB/ HIF1a signaling

Next, we firstly performed a search for possible transcription factor-binding sites in the promoter region of GLUT1 using Matlnspector

(http://www.genomatix.de/online help/ help_matinspector/matinspector_help.html), Alggen Promo (http://alggen.Isi.upc.es/cgi-bin/promo_v3/promo/promoinit.cgi? dirDB=TF_8.3) and JASPAR (http://jaspar.binf.ku.dk/). Then, we observed that the promoter region contained several transcription factor-binding elements, among which we found that NF-KBbinding site located in the GLUT1 upstream (-941/-930 nt) was conserved and could be detected by the three databases (data not shown). Moreover, NF-KB as a reported target of aspirin was frequently involved in the aspirin-mediated modulation of cellular metabolism and proliferation [38-40], which has been validated that aspirin could down-regulate the expression of NF-KB (data not shown). Thus, we speculated that aspirin might regulate the transcription of GLUT1 through NF-KB.

To validate the core region regulated by NF-KB, we cloned a series of fragments of GLUT1 promoter. Various lengths of the GLUT1 $5^{\prime}$ flanking region, including $-1306 /+197$ (pGL3-P1),
$-1008 /+197$ (pGL3-P2), $-780 /+197 \quad$ (pGL3-P3), $\quad-459 /+197$ (pGL3-P4) and -126/+197 (pGL3-P5) were cloned and transiently transfected into the HepG2 cells, respectively. PDTC, an inhibitor of NF-KB, obviously decreased the activities of GLUT1 promoter fragments except pGL-P3, pGL-P4, and pGL-P5, indicating that the $-1008 /-780$ region in GLUT1 promoter is the regulatory target sequence of NF-KB (Fig. 4a), which is consistent with the bioinformatics result. In addition, PDTC failed to regulate the PGL-P1 mut activity when NF-KB binding site was mutated in HepG2 and 293T cells (Fig. 4b and Supplementary Figure 4A). Next, RT-qPCR and Western blot assays validated that PDTC could robustly inhibit the expression of GLUT1 at the levels of mRNA and protein in HepG2 and H7402 cells in a dose-dependent manner, supporting that NF-KB can regulate GLUT1 (Fig. 4c and Supplementary Figure 4B). Meanwhile, the inhibition efficiency of PDTC was evaluated by Western blot analysis (Supplementary Figure 4C). Furthermore, we assessed the effects of PDTC on the levels of ROS and glucose uptake. Our data showed that the treatment with $50 \mu \mathrm{M}$ PDTC significantly decreased the intracellular levels of ROS and glucose consumption in HepG2 and H7402 cells. Strikingly, overexpression of GLUT1 could increase the levels of intracellular ROS and glucose consumption pretreated with 50 $\mu M$ PDTC (Fig. 4d, e), suggesting that aspirin downregulates GLUT1 via transcriptional factor NF-KB in modulation of glucose 
a
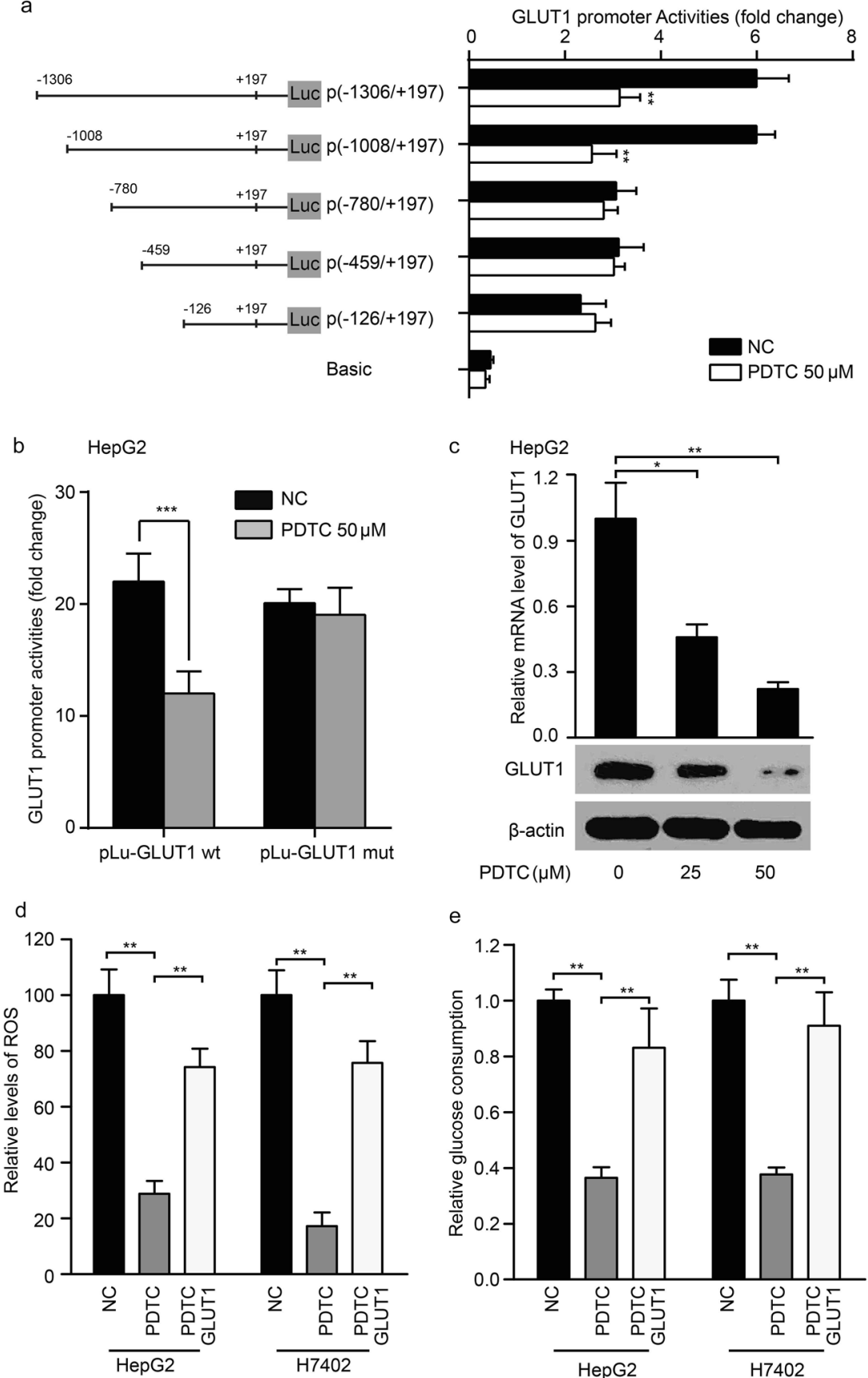

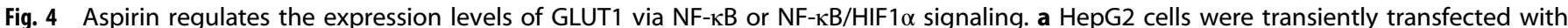
pGL3-Basic $\left(0.2 \mu \mathrm{g} /\right.$ well) or reporter constructs containing various lengths of the $5^{\prime}$-flanking region of the GLUT1 gene, as indicated (pGL3-P1, pGL3-P2, pGL3-P3, pGL3-P4, and pGL3-P5, respectively). Then every group was respectively treated with $50 \mu M$ PDTC or DMSO. b Luciferase reporter gene assay was measured in HepG2 cells transiently transfected with pGL3-P1 or pGL3-P1 mut $(0.2 \mu \mathrm{g} / \mathrm{well})$ and treated with $50 \mu \mathrm{M}$ PDTC or DMSO. c The expression levels of GLUT1 in HepG2 cells were separately examined by RT-qPCR and Western blot assay. The cells were treated with indicated concentrations of PDTC for $48 \mathrm{~h}$. d ROS detection assays in the HepG 2 and H7402 cell lines with single treatment of PDTC for $48 \mathrm{~h}$ or the co-treatment of PDTC and pCDNA-GLUT1, respectively. e Glucose consumption assays in the HepG2 and H7402 cell lines with single treatment of PDTC for $48 \mathrm{~h}$ or the co-treatment of PDTC and pCDNA-GLUT1, respectively. The supernatant was used for the measurement of glucose by glucose-lactate biosense tester SBA-40E. Statistical significant differences are indicated: ${ }^{*} P<0.05,{ }^{* *} P<0.01,{ }^{* * *} P$ $<0.001$, Student's $t$-test for (b), one-way ANOVA for (c-e). All experiments were performed at least three times

metabolism in hepatoma cells. It has been reported that HIF1a as an important transcription factor is involved in the hypoxic response of cells, and functions in tumor development and progression. Cytokines that activate NF-KB may increase HIF1a expression by driving increased transcription and HIFla is a transcriptional factor of GLUT1 [41, 42]. Accordingly, RT-qPCR assays showed that $\mathrm{CoCl}_{2}$-activated HIF1a expression could slightly rescue the GLUT1 expression inhibited by aspirin or PDTC, suggesting that aspirin depressed GLUT1 through targeting NF-KB or NF-KB/HIF1a signaling (Supplementary Fig. 4D). The expression 

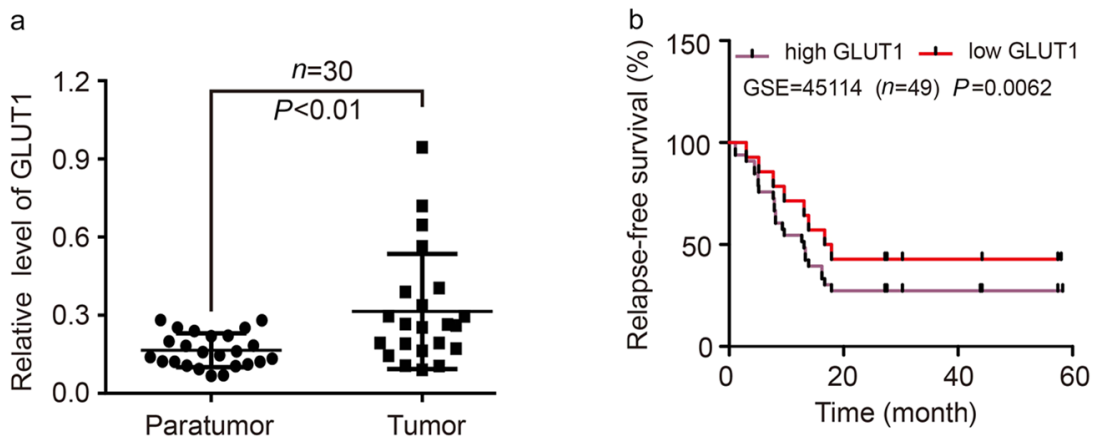

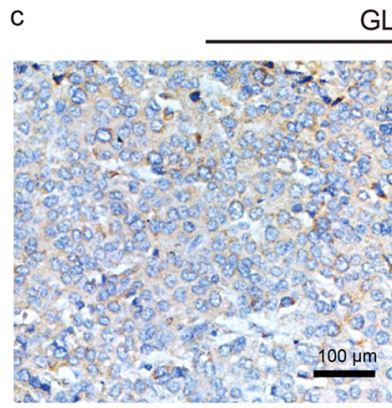

Normal liver tissues

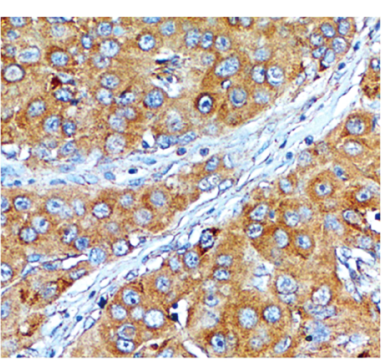

HCC tissues

Fig. 5 High expression of GLUT1 displays poor prognosis in clinical HCC tissues. a Relative mRNA levels of GLUT1 were examined by RT-qPCR in 30 pairs of HCC tissues and corresponding adjacent normal tissues. The correlation of GLUT1 expression between tumor and adjacent normal tissue was determined by unpaired $t$-test. b Relapse-free survival analysis of 49 HCC patients with low versus high GLUT1 expression (Gehan-Breslow-Wilcoxon test, $P=0.0062$ ). The low and high expression groups of GLUT1 were defined by comparing with the median expression value of patients in this study. c IHC staining of GLUT1 in the normal liver tissues and HCC tissues from HCC tissue microarray. ${ }^{*} P<$ 0.01 , Student's $t$-test. All experiments were performed at least three times

of HIF1a was examined by RT-qPCR (Supplementary Fig. 4E). Thus, we conclude that aspirin regulates the expression of GLUT1 via NF-KB or NF-KB/HIF1a signaling in liver cancer cells.

High expression of GLUT1 displays poor prognosis in clinical HCC tissues

Next, we demonstrated the significance of GLUT1 in clinic. RTqPCR showed that the mRNA levels of GLUT1 were higher in HCC tissues than those in their adjacent normal liver tissues in 30 paired clinical HCC samples (Fig. 5a). Then, we proposed whether aspirin modulated GLUT1 in decreasing the glucose uptake in hepatoma cells. Moreover, we analyzed a publicly available HCC patient GEO dataset (GEO Accession, GSE45114). Strikingly, we observed that the high expression of GLUT1 was significantly correlated with a poor relapse-free survival ( $P=0.0062$, Fig. $5 b)$, suggesting that GLUT1 may play a crucial role in hepatocarcinogenesis. Additionally, we evaluated the expression of GLUT1 by immunohistochemical (IHC) staining in clinical HCC tissues using tissue microarrays and found that $79.72 \%$ (114/143) showed high expression levels of GLUT1 in 143 HCC liver tissues, in which Grade III HCC was $90.4 \%$ (103/114). However, in the normal liver tissues, only 1 out $8(12.5 \%)$ yielded positive signal, indicating that GLUT1 is highly expressed in clinical HCC patients (Fig. 5c). Taken together, we conclude that high expression of GLUT1 displays poor prognosis in clinical HCC tissues.

Aspirin depresses hepatoma cell proliferation by GLUT1-mediated glucose metabolism

Next, we concerned whether aspirin suppressed the proliferation of liver cancer cells and glucose metabolism through downregulating GLUT1. As expected, cell viability assays showed that aspirin suppressed the proliferation of HepG2 cells, which could be rescued by ectopic expression of GLUT1 (Fig. 6a). Moreover, EdU assays displayed the consistent results in the cells (Fig. 6b), indicating that aspirin suppresses the cell proliferation through GLUT1. Meanwhile, ROS detection and glucose consumption assays demonstrated that the overexpression of GLUT1 efficiently disrupted the aspirin-mediated reduction of ROS levels and glucose consumption in HepG2 cells, suggesting that aspirin modulates glucose metabolism through down-regulating GLUT1 (Fig. 6c, d). To examine the significance of GLUT1 when aspirin functions, we established the HepG2-shGLUT1 cells using lentiviral syetem. The stable knockdown efficiency of GLUT1 was validated by RT-qPCR and Western blot analysis (Fig. 6e). Surprisingly, we observed that aspirin failed to work by cell viability assays in the HepG2 cells (Fig. 6f), suggesting that GLUT1 plays a crucial role in response to suppression of HCC mediated by aspirin. In addition, we repeated the data by transient transfection of siGLUT1 in HepG2 cells (Supplementary Figure 6B). The efficiency of GLUT1 mRNA interference was examined by RT-qPCR (Supplementary Fig. 6A). Taken together, we conclude that aspirin depresses hepatoma cell proliferation by GLUT1-mediated glucose metabolism.

Aspirin inhibits the growth of liver cancer cells and the expression of GLUT1 in vivo

Next, we further evaluated the effect of aspirin on the proliferation of hepatoma cells and the expression level of GLUT1 in vivo. We observed that the tumorigenicity was remarkably suppressed in nude mice given aspirin $(75 \mathrm{mg} / \mathrm{kg})$ by intragastric gavage (Fig. $7 \mathrm{a}-\mathrm{c}$ ). In addition, the staining of Ki-67, a marker of proliferation, further attested that the aspirin inhibited tumor 

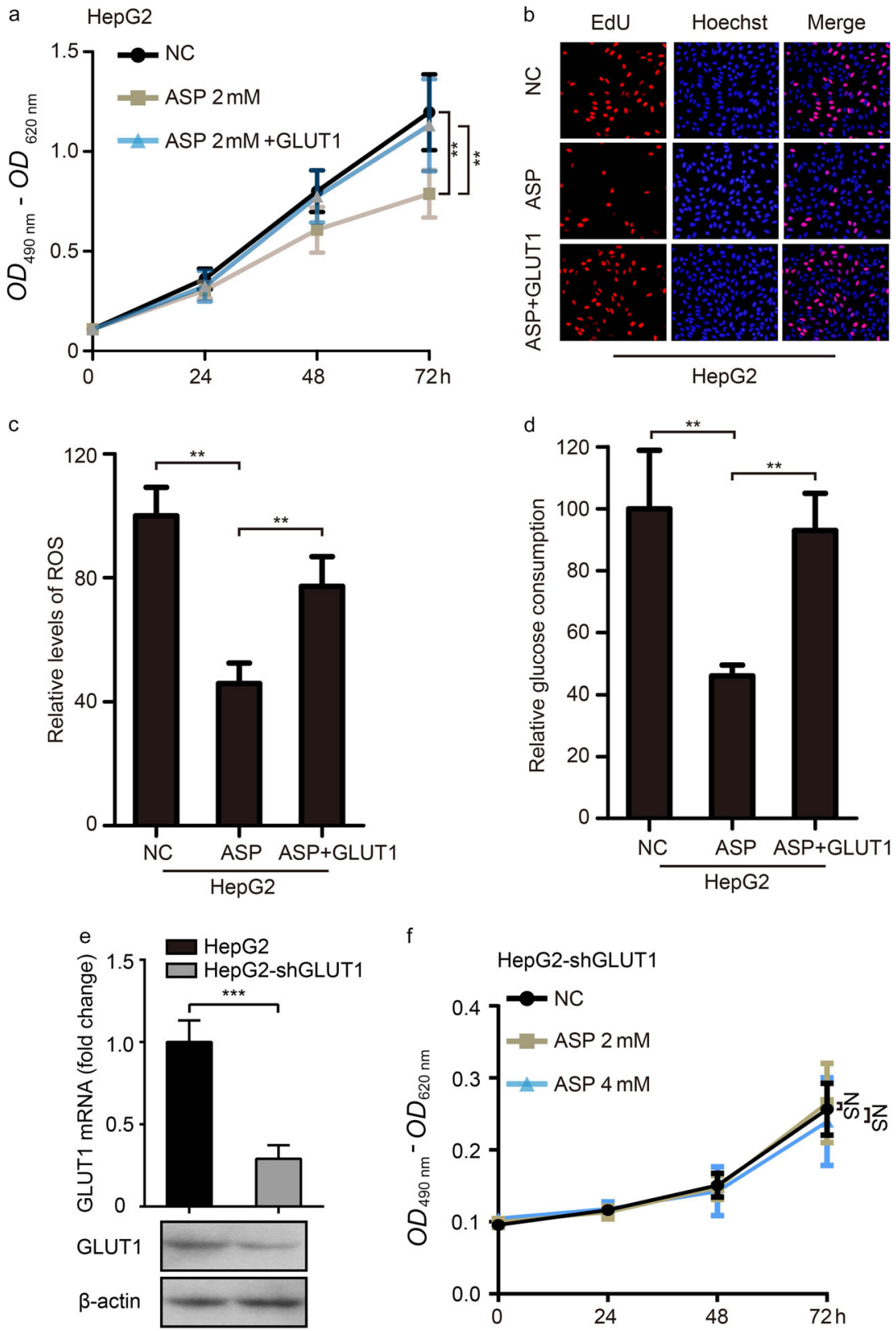

Fig. 6 Aspirin depresses hepatoma cell proliferation by GLUT1-mediated glucose metabolism. a Cell viability assays in HepG2 cells treated with DMSO or aspirin $(2 \mathrm{mM})$ for indicated time courses after transiently transfected with pcDNA3.1 or pcDNA3.1-GLUT1. b EdU assays in HepG2 cells treated with DMSO or aspirin $(2 \mathrm{mM})$ for $48 \mathrm{~h}$ after transiently transfected with pCDNA3.1 or pCDNA3.1-GLUT1. c ROS detection assays in HepG2 cells treated with DMSO or aspirin $(2 \mathrm{mM})$ for $48 \mathrm{~h}$ after transiently transfected with pCDNA 3.1 or pCDNA-GLUT1. d Glucose consumption assays in HepG2 cells treated with DMSO or aspirin ( $2 \mathrm{mM})$ for $48 \mathrm{~h}$ after transiently transfected with pcDNA 3.1 or pcDNAGLUT1. The supernatant was used for the measurement of glucose by glucose-lactate biosense tester SBA-40E. e The expression levels of GLUT1 were separately detected by RT-qPCR assay (up) and Western blot assay (down), in HepG2 and HepG2-shGLUT1 cells. The cells were treated with indicated concentrations of aspirin for $48 \mathrm{~h}$. $\mathbf{f}$ Cell viability assays in HepG2-shGLUT1 cells treated with different concentrations of aspirin for indicated time courses. Statistical significant differences are indicated: ${ }^{* *} P<0.01,{ }^{* *} P<0.001$, NS, no significance, Student's $t$-test for (a), (e) and (f), one-way ANOVA for (c) and (d). All experiments were performed at least three times

growth (Fig. 7d), suggesting that aspirin can restrain the growth of hepatoma in vivo. Western blot analysis and RT-qPCR showed that the expression of GLUT1 was significantly lower in the group given aspirin than that in the group given normal saline (Fig. 7e, f). Collectively, we conclude that aspirin can suppress the growth of liver cancer cell through down-regulating the expression of GLUT1 in vivo.

\section{DISCUSSION}

It has been reported that aspirin, a non-steroidal anti-inflammatory drug, is widely used for the prevention and treatment of many diseases $[13,38]$. Recently, Lee and colleagues reported that aspirin prevented the development of HCC [43]. We previously reported that aspirin suppressed the abnormal lipid metabolism in hepatoma cells [21]. However, whether aspirin could regulate the 

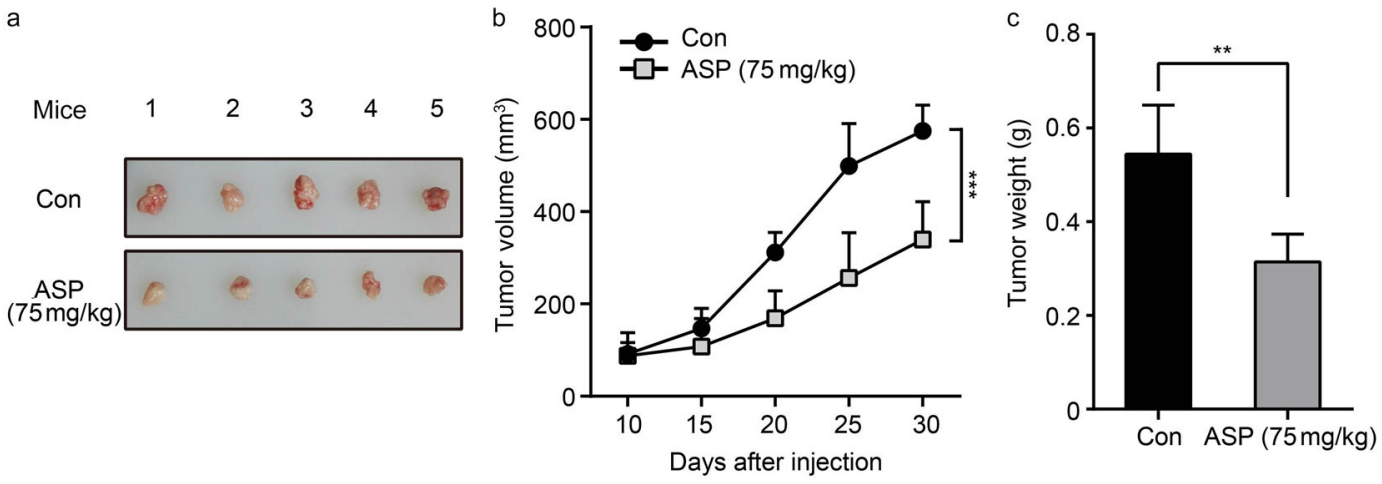

d $\mathrm{Ki}-67$
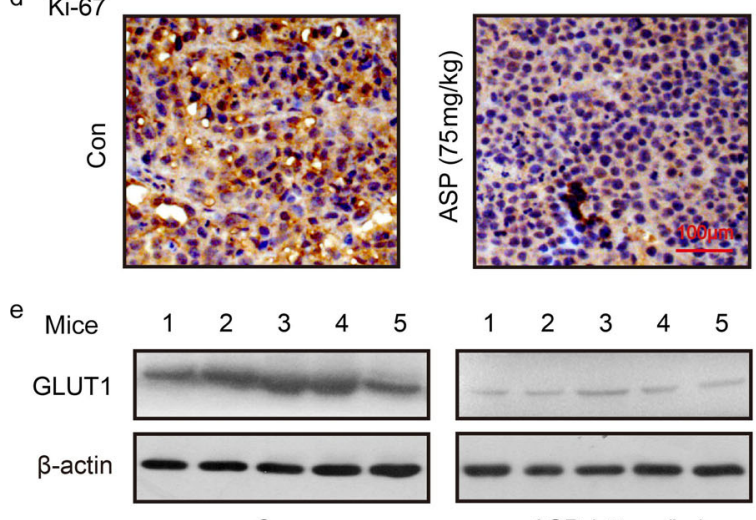

Con
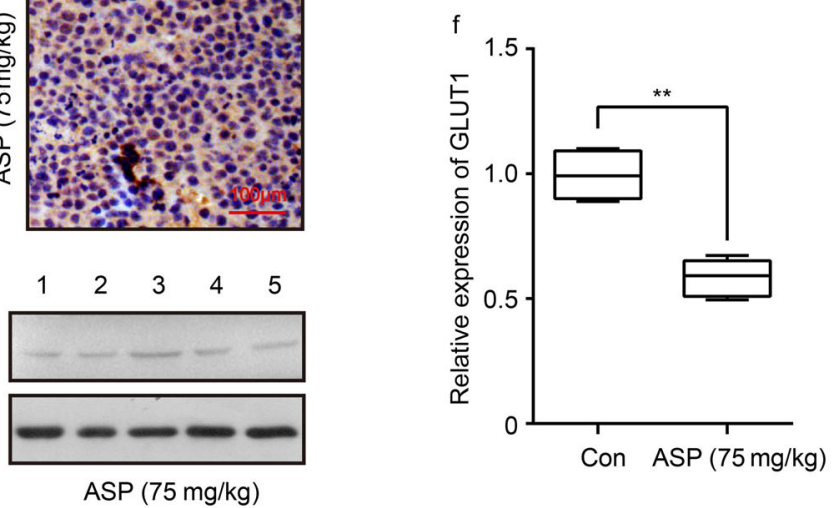

Fig. 7 Aspirin inhibits the proliferation of liver cancer cells and the expression of GLUT1 in vivo. a The photographs of dissected tumors from nude mice. $\mathbf{b}$, $\mathbf{c}$ the growth curve and average weight of the tumors transplanted with HepG2 cells by intragastric gavage with either normal saline (vehicle) or aspirin (suspended in physiological saline, $75 \mathrm{mg} / \mathrm{kg}$ ) in nude mice. $\mathbf{d}$ The expression of Ki-67 in the tumor tissues from mice was detected by IHC. e The protein expression levels of GLUT1 were examined by Western blot in the tumor tissues from nude mice, respectively. $f$ The mRNA levels of GLUT1 were examined by RT-qPCR in the tumor tissues from nude mice, respectively. Error bars represent means \pm SD $(n=3)$. Statistical significant differences are indicated: ${ }^{* *} P<0.01 ;{ }^{* * *} P<0.001$; Student's $t$-test

glucose metabolism in suppression of liver cancer is poorly understood. In this study, we investigated the significance of aspirin in the modulation of glucose metabolism.

We applied cell viability, colony formation and EdU assays to estimate the effects of aspirin on the cell proliferation. Notably, we found that aspirin could suppress the proliferation of liver cancer cells in a dose-dependent manner, suggesting that aspirin plays a vital role in hepatocarcinogenesis. Cancer was recognized as a disease of altered metabolism for nearly 100 years, however, metabolic disorder has much more recently been recognized as an essential hallmark of neoplasia [44]. Glucose is the most abundant nutrient in blood, and is commonly utilized by tumor cells to meet their increased energy demand [45]. To better understand the significance of aspirin in modulating glucose metabolism, we first measured the effects of aspirin on ROS levels and glucose consumption in hepatoma cells. Strikingly, aspirin remarkably decreased the ROS levels and glucose consumption in hepatoma cells. Therefore, our finding provides evidence that aspirin modulates glucose metabolism in liver cancer.

Next, we try to identify the mechanism by which aspirin regulates glucose metabolism. We screened the effect of aspirin on the glucose metabolism related factors including GLUT1, G6PD, HIF1a, SCO2, and PDHA1. Strikingly, we identified that the expression of GLUT1 and HIF1a, hypoxia-associated responses, was suppressed by aspirin. The HIF1 is a key mediator of cellular adaptation to hypoxia. It is continuously degraded in normoxia but stabilized and activated under hypoxic conditions. The target genes of HIF1 increase oxygen delivery through increasing expression of glucose transporters and glycolytic enzymes [46]. In this study, we demonstrated that aspirin might regulate the transcription of GLUT1 by luciferase reporter gene assays. It suggests that aspirin can decrease the expression of GLUT1 through inhibiting the transcription of GLUT1. Moreover, we observed that there is a NF-KB binding site in the GLUT1 promoter (-941/-930 nt) by MatInspector, Alggen Promo and JASPAR. It has been reported that aspirin induces nuclear caspasedependent cleavage of Sp1, Sp3, and Sp4 proteins and inhibits the activity of NF-KB [47-49], which plays pivotal roles in diverse physiological and pathological processes including proliferation, migration, invasion, metastasis, and apoptosis [50, 51]. In addition, RRAD, a member of the Ras-like small GTPase Family, inhibits the GLUT1 translocation and the Warburg effect in lung cancer cells via downregulating the NF-KB signaling [7]. To better understand the underlying mechanism by which aspirin affected GLUT1, we assessed the influence of PDTC, an inhibitor of NF-kB, on the promoter activity of GLUT1 in 293T and HepG2 cells. Luciferase reporter gene assay confirmed that the core region regulated by NF-kB was located in the GLUT1 upstream -1008/-780 region, which is consistent with the predicted site by MatInspector, Alggen Promo, and JASPAR. Strikingly, our observations indicated that PDTC was able to downregulate the expression of GLUT1 in hepatoma cells. Notably, we observed that treatments with PDTC were able to obviously decrease the ROS levels and glucose consumption in cells, which could be mostly rescued by the overexpression of GLUT1. It suggests that NF-KB is involved in the aspirin-mediated regulating of GLUT1 in the process of glucose metabolism in hepatoma cells. In addition, Kao and colleagues reported that ET-1 may activate GLUT1 transcription by enhancing interaction between nuclear NF-KB and Sp1 as well as their binding to enhancer 2 [52]. Therefore, our data that aspirin 
regulates GLUT1 expression by NF-KB in liver cancer are consistent with the reports. It has been reported that cytokines that activate NF-KB may increase HIF1a expression by driving increased transcription [41]. HIF-1 activates the transcription of genes that are involved in crucial aspects of cancer biology, including angiogenesis, glucose metabolism, cell survival, and invasion [53, 54]. Nearly 100 HIF-1 target genes have been identified [53, 55]. In this study, we found that aspirin could cause HIF1 a degradation in liver cancer and $\mathrm{CoCl}_{2}$-activated HIF1a expression could slightly rescue the GLUT1 expression inhibited by aspirin or PDTC. It suggests that aspirin may depress liver cancer by HIF1a pathway. Thus, we can conclude that aspirin regulates the expression of GLUT1 via NF-KB or NF-KB/HIF1a signaling in liver cancer cells.

Clinically, we discovered that GLUT1 was abundantly expressed in tumor tissues compared with adjacent normal tissues in 30 pairs of clinical HCC samples. Analysis of GEO data displayed that high expression level of GLUT1 was positively correlated with poor relapse-free survival. IHC staining using clinical HCC tissue microarrays showed that GLUT1 was closely associated with liver tumor malignancy. In addition, bioinformatics analysis (http:// merav.wi.mit.edu/) also validated that GLUT1 was highly expressed in clinical HCC (data not shown). Our data suggest that GLUT1 plays a crucial role in the development of liver cancer. Functionally, we validated that aspirin depressed cell proliferation of hepatoma by GLUT1-mediated glucose metabolism in vitro and in vivo. In addition, we observed that high dose of glucose $(20 \mathrm{mg} /$ $\mathrm{mL}$ ) in the culture media didn't antagonize the effect of aspirin on cell proliferation and ROS (data not shown). It suggests that aspirin-suppressed GLUT1 blocks the uptake of glucose in hepatoma cells. Taken together, we conclude that GLUT1 may serve as a novel target for HCC and aspirin is able to widely affect the metabolism events in liver cancer.

In summary, we uncover that aspirin modulates abnormal glucose metabolism in hepatoma cells via NF-KB (or NF-KB/HIF1a)/ GLUT1 signaling, leading to the inhibition of cell proliferation. Our finding provides new insights into the mechanism by which aspirin depresses glucose metabolism in hepatocarcinogenesis.

\section{ACKNOWLEDGEMENTS}

This work was supported in part by National Basic Research Program of China (973 Program, No. 2015CB553703) and National Natural Science Foundation of China (No. 31670769, No. 31470756).

\section{AUTHOR CONTRIBUTIONS}

$X Z$ conceived the projects, designed the experiments, and drafted the manuscript. $Y L$ and JF designed the experiments and drafted the manuscript. $Y L, J F, M S, B L, G Y, Y B$, $M Z$, and TW performed the experiments. MS and WZ analyzed the experiments shown in all of the figures. HY provided technical assistance. All authors reviewed the results and approved the final version of the manuscript.

\section{ADDITIONAL INFORMATION}

The online version of this article (https://doi.org/10.1038/s41401-018-0014-x) contains supplementary material, which is available to authorized users.

Conflict of interest: The authors declare that they have no conflict of interest.

\section{REFERENCES}

1. El-Serag HB, Rudolph KL. Hepatocellular carcinoma: epidemiology and molecular carcinogenesis. Gastroenterology. 2007;132:2557-76.

2. Forner A, Llovet JM, Bruix J. Hepatocellular carcinoma. Lancet. 2012;379:1245-55.

3. Zhang T, Zhang J, You X, Liu Q, Du Y, Gao Y, et al. Hepatitis B virus X protein modulates oncogene Yes-associated protein by CREB to promote growth of hepatoma cells. Hepatology. 2012;56:2051-9.

4. Ma C, Kesarwala AH, Eggert T, Medina-Echeverz J, Kleiner DE, Jin P, et al. NAFLD causes selective $\mathrm{CD} 4(+) \mathrm{T}$ lymphocyte loss and promotes hepatocarcinogenesis. Nature. 2016;531:253-7.
5. Endig J, Buitrago-Molina LE, Marhenke S, Reisinger F, Saborowski A, Schutt J, et al. Dual role of the adaptive immune system in liver injury and hepatocellular carcinoma development. Cancer Cell. 2016;30:308-23.

6. Gao Y, Feng J, Yang G, Zhang S, Liu Y, Bu Y, et al. Hepatitis B virus X proteinelevated MSL2 modulates hepatitis B virus covalently closed circular DNA by inducing degradation of $\mathrm{APOBEC} B \mathrm{~B}$ to enhance hepatocarcinogenesis. Hepatology. 2017;66:1413-29.

7. Liu J, Zhang C, Wu R, Lin M, Liang Y, Liu J, et al. RRAD inhibits the Warburg effect through negative regulation of the NF-kappaB signaling. Oncotarget. 2015;6:14982-92.

8. Martinez-Outschoorn UE, Peiris-Pages M, Pestell RG, Sotgia F, Lisanti MP. Cancer metabolism: a therapeutic perspective. Nat Rev Clin Oncol. 2017;14:11-31.

9. Poyton RO, Ball KA, Castello PR. Mitochondrial generation of free radicals and hypoxic signaling. Trends Endocrinol Metab. 2009;20:332-40.

10. Mueckler M, Thorens B. TheSLC2 (GLUT) family of membrane transporters. Mol Asp Med. 2013;34:121-38.

11. Airley RE, Mobasheri A. Hypoxic regulation of glucose transport, anaerobic metabolism and angiogenesis in cancer: novel pathways and targets for anticancer therapeutics. Chemotherapy. 2007;53:233-56.

12. Medina RA, Owen Gl. Glucose transporters: expression, regulation and cancer. Biol Res. 2002;35:9-26.

13. Rothwell PM, Wilson M, Price JF, Belch JF, Meade TW, Mehta Z. Effect of daily aspirin on risk of cancer metastasis: a study of incident cancers during randomised controlled trials. Lancet. 2012;379:1591-601.

14. Huang Q, Li J, Xing J, Li W, Li H, Ke X, et al. CD147 promotes reprogramming of glucose metabolism and cell proliferation in HCC cells by inhibiting the p53dependent signaling pathway. J Hepatol. 2014;61:859-66.

15. Tang MJ, Ho S, Chan SK, Le ND, Suh KW, Kim YB, et al. Aspirin and chemotherapy synergistically enhances apoptosis and promotes tumor regression by decreasing coxl and cox2 levels to increase survival of colorectal cancer patients. Gastroenterology. 2009;136:A748

16. Sun X, Han F, Yi J, Han L, Wang B. Effect of aspirin on the expression of hepatocyte NF-kappaB and serum TNF-alpha in streptozotocin-induced type 2 diabetic rats. J Korean Med Sci. 2011;26:765-70.

17. Drew DA, Cao Y, Chan AT. Aspirin and colorectal cancer: the promise of precision chemoprevention. Nat Rev Cancer. 2016;16:173-86.

18. Saha S, Mukherjee S, Khan P, Kajal K, Mazumdar M, Manna A, et al. Aspirin suppresses the acquisition of chemoresistance in breast cancer by disrupting an NFkappaB-IL6 signaling axis responsible for the generation of cancer stem cells. Cancer Res. 2016;76:2000-12.

19. Lee M, Chung GE, Lee JH, Oh S, Nam JY, Chang Y, et al. Antiplatelet therapy and the risk of hepatocellular carcinoma in chronic hepatitis B patients on antiviral treatment. Hepatology. 2017;66:1556-69.

20. Fendrich V, Chen NM, Neef M, Waldmann J, Buchholz M, Feldmann G, et al. The angiotensin-l-converting enzyme inhibitor enalapril and aspirin delay progression of pancreatic intraepithelial neoplasia and cancer formation in a genetically engineered mouse model of pancreatic cancer. Gut. 2010;59:630-7.

21. Yang $G$, Wang $Y$, Feng J, Liu $Y$, Wang $T$, Zhao $M$, et al. Aspirin suppresses the abnormal lipid metabolism in liver cancer cells via disrupting an NFkappaB-ACSLI signaling. Biochem Biophys Res Commun. 2017;486:827-32.

22. Hundal RS, Petersen KF, Mayerson AB, Randhawa PS, Inzucchi S, Shoelson SE, et al. Mechanism by which high-dose aspirin improves glucose metabolism in type 2 diabetes. J Clin Invest. 2002;109:1321-6.

23. Abiru S, Nakao K, Ichikawa T, Migita K, Shigeno M, Sakamoto M, et al. Aspirin and NS-398 inhibit hepatocyte growth factor-induced invasiveness of human hepatoma cells. Hepatology. 2002;35:1117-24.

24. Vannini F, Kodela R, Chattopadhyay M, Kashfi K. NOSH-aspirin inhibits colon cancer cell growth: effects of positional isomerism. Redox Biol. 2015;5:421.

25. Shackelford DB, Abt E, Gerken L, Vasquez DS, Seki A, Leblanc M, et al. LKB1 inactivation dictates therapeutic response of non-small cell lung cancer to the metabolism drug phenformin. Cancer Cell. 2013;23:143-58.

26. Xu F, You X, Liu F, Shen X, Yao Y, Ye L, et al. The oncoprotein HBXIP up-regulates Skp2 via activating transcription factor E2F1 to promote proliferation of breast cancer cells. Cancer Lett. 2013;333:124-32.

27. Liu F, Ma F, Wang $\mathrm{Y}$, Hao L, Zeng $\mathrm{H}$, Jia $\mathrm{C}$, et al. PKM2 methylation by CARM1 activates aerobic glycolysis to promote tumorigenesis. Nat Cell Biol. 2017;19:1358-70.

28. Wu XL, Wang LK, Yang DD, Qu M, Yang YJ, Guo F, et al. Effects of Glutl gene silencing on proliferation, differentiation, and apoptosis of colorectal cancer cells by targeting the TGF-beta/PI3K-AKT-mTOR signaling pathway. J Cell Biochem. 2018;119:2356-67.

29. Cheng R, Liu YJ, Cui JW, Yang M, Liu XL, Li P, et al. Aspirin regulation of c-myc and cyclinDI proteins to overcome tamoxifen resistance in estrogen receptor-positive breast cancer cells. Oncotarget. 2017;8:30252-64. 
30. Cho M, Kabir SM, Dong Y, Lee E, Rice VM, Khabele D, et al. Aspirin blocks EGFstimulated cell viability in a COX-1 dependent manner in ovarian cancer cells. J. Cancer. 2013;4:671-8.

31. Fontaine $E$, McShane J, Page R, Shackcloth M, Mediratta N, Carr M, et al. Aspirin and non-small cell lung cancer resections: effect on long-term survival. Eur J Cardio-Thorac Surg. 2010;38:21-6.

32. Li XF, Xu BZ, Wang SZ. Aspirin inhibits the proliferation and migration of gastric cancer cells in p53-knockout mice. Oncol Lett. 2016;12:3183-6.

33. Risch HA. Aspirin and Pancreatic Cancer-Response. Cancer epidemiology, biomarkers \& prevention: a publication of the American Association for Cancer Research, cosponsored by the American Society of Preventive. Cancer Epidemiol. 2017;26:979.

34. Zumwalt TJ, Wodarz D, Komarova NL, Toden S, Turner J, Cardenas J, et al. Aspirininduced chemoprevention and response kinetics are enhanced by PIK3CA mutations in colorectal cancer cells. Cancer Prev Res. 2017;10:208-18.

35. Fang Z, Jiang C, Feng Y, Chen R, Lin X, Zhang Z, et al. Effects of G6PD activity inhibition on the viability, ROS generation and mechanical properties of cervical cancer cells. Biochim Et Biophys Acta. 2016;1863:2245-54.

36. Kai AK, Chan LK, Lo RC, Lee JM, Wong CC, Wong JC, et al. Down-regulation of TIMP2 by HIF-1alpha/miR-210/HIF-3alpha regulatory feedback circuit enhances cancer metastasis in hepatocellular carcinoma. Hepatology. 2016;64:473-87.

37. Liu F, Zhang W, You X, Liu Y, Li Y, Wang Z, et al. The oncoprotein HBXIP promotes glucose metabolism reprogram-ming via downregulating $\mathrm{SCO} 2$ and PDHA1 in breast cancer. Oncotarget. 2015;6:27199-213.

38. Liao D, Zhong L, Duan T, Zhang RH, Wang X, Wang G, et al. Aspirin suppresses the growth and metastasis of osteosarcoma through the NF-kappaB pathway. Clin Cancer Res. 2015;21:5349-59.

39. Chattopadhyay M, Kodela R, Nath N, Barsegian A, Boring D, Kashfi K. Hydrogen sulfide-releasing aspirin suppresses NF-kappaB signaling in estrogen receptor negative breast cancer cells in vitro and in vivo. Biochem Pharmacol. 2012:83:723-32.

40. Huang L, Mackenzie GG, Sun Y, Ouyang N, Xie G, Vrankova K, et al. Chemotherapeutic properties of phospho-nonsteroidal antiinflammatory drugs, a new class of anticancer compounds. Cancer Res. 2011;71:7617-27.

41. Rius J, Guma M, Schachtrup C, Akassoglou K, Zinkernagel AS, Nizet V, et al. NFkappaB links innate immunity to the hypoxic response through transcriptional regulation of HIF-lalpha. Nature. 2008;453:807-11.
42. Chen C, Pore N, Behrooz A, Ismail-Beigi F, Maity A. Regulation of glutl mRNA by hypoxia-inducible factor-1. Interaction between $\mathrm{H}$-ras and hypoxia. J Biol Chem. 2001;276:9519-25.

43. Lee M, Chung GE, Lee JH, Oh S, Nam JY, Chang Y, et al. Antiplatelet therapy and the risk of hepatocellular carcinoma in chronic hepatitis $B$ patients on antiviral treatment. Hepatology. 2017;66:1556-69.

44. Hanahan D, Weinberg RA. Hallmarks of cancer: the next generation. Cell. 2011;144:646-74.

45. Boroughs LK, DeBerardinis RJ. Metabolic pathways promoting cancer cell survival and growth. Nat Cell Biol. 2015;17:351-9.

46. Semenza GL. Regulation of metabolism by hypoxia-inducible factor 1. Cold Spring Harb Symp Quant Biol. 2011;76:347-53.

47. Pathi S, Jutooru I, Chadalapaka G, Nair V, Lee SO, Safe S. Aspirin inhibits colon cancer cell and tumor growth and down-regulates specificity protein (Sp) transcription factors. PLoS One. 2012;7:e48208.

48. Kopp E, Ghosh S. Inhibition of NF-kappa B by sodium salicylate and aspirin. Science. 1994;265:956-9.

49. Yin MJ, Yamamoto Y, Gaynor RB. The anti-inflammatory agents aspirin and salicylate inhibit the activity of I(kappa)B kinase-beta. Nature. 1998;396:77-80.

50. Yang X, Lu H, Yan B, Romano RA, Bian Y, Friedman J, et al. DeltaNp63 versatilely regulates a broad NF-kappaB gene program and promotes squamous epithelial proliferation, migration, and inflammation. Cancer Res. 2011;71:3688-3700.

51. Pacak K, Sirova M, Giubellino A, Lencesova L, Csaderova L, Laukova M, et al. NFkappaB inhibition significantly upregulates the norepinephrine transporter system, causes apoptosis in pheochromocytoma cell lines and prevents metastasis in an animal model. Int J Cancer. 2012;131:2445-55.

52. Kao YS, Fong JC. Endothelin-1 induces glutl transcription through enhanced interaction between $\mathrm{Spl}$ and NF-kappaB transcription factors. Cell Signal. 2008;20:771-8.

53. Ke Q, Costa M. Hypoxia-inducible factor-1 (HIF-1). Mol Pharmacol. 2006;70:1469-80.

54. Luo $\mathrm{D}$, Wang $\mathrm{Z}, \mathrm{Wu} J$, Jiang $\mathrm{C}, \mathrm{Wu}$ J. The role of hypoxia inducible factor-1 in hepatocellular carcinoma. Biomed Res Int. 2014;2014:409272.

55. Semenza GL. Targeting HIF-1 for cancer therapy. Nat Rev Cancer. 2003;3:721-32. 